\title{
Effects of Auditory Training and Remote Microphone Technology on the Behavioral Performance of Children and Young Adults Who Have Autism Spectrum Disorder
}

DOI: $10.3766 /$ jaaa.18062

\author{
Erin C. Schafer* \\ Kamakshi V. Gopal* \\ Lauren Mathews* \\ Skyler Thompson* \\ Kara Kaiser* \\ Sarah McCullough* \\ Jessalyn Jones $\dagger$ \\ Priscilla Castillo* \\ Emilee Canale* \\ Avery Hutcheson*
}

\begin{abstract}
Background: Individuals who have a normal pure-tone audiogram but are diagnosed with autism spectrum disorder (ASD) often exhibit poorer speech recognition and auditory processing when compared with neurotypical peers with normal pure-tone audiograms.

Purpose: The purpose of this study was to determine the efficacy and effectiveness of a 12-week auditory processing training (APT) program that was designed to address the deleterious effects of background noise and auditory processing deficits that are common among individuals diagnosed with ASD.

Research Design: A repeated measures design was used.

Study Sample: The sample consisted of 15 high-functioning children and young adults who had a formal diagnosis of ASD and who were recruited from local clinics and school districts.

Intervention: Participants completed the 12-week APT program consisting of computerized dichotic training, one-on-one therapist-directed auditory training, and the use of remote microphone (RM) technology at home and in the classroom.

Data Collection and Analysis: Participants completed a comprehensive test battery to assess general auditory processing skills, speech recognition in noise, acceptance of background noise, spatial processing, binaural integration abilities, self-perceived difficulties, and observed behaviors. Testing was conducted before $(n=15)$, immediately after $(n=15)$, and 12 weeks after $(n=7)$ the completion of the APT program. Paired $t$-tests, repeated measures analysis of variance, or nonparametric tests were used to analyze the data.

Results: On average, the APT program significantly enhanced general auditory processing abilities, including binaural integration and subjective listening abilities in the classroom. When the RM was used, significantly improved speech recognition and improved acceptance of background noise was measured relative to a condition with no technology.
\end{abstract}

*University of North Texas, Denton, TX; †Rady Children's Hospital, San Diego, CA

Corresponding author: Erin C. Schafer, University of North Texas, Denton, TX 76203-5017; Email: erin.schafer@unt.edu

This study was funded by a research grant from the Texas Higher Education Coordinating Board.

Portions of this manuscript have been presented at the American Academy of Audiology conferences in 2017 and 2018, the American SpeechLanguage-Hearing Association in 2017, and the Educational Audiology Conference in 2017. 
Conclusions: Following the APT program, the participants exhibited the greatest improvements in testing that required binaural integration and auditory working memory. The use of the RM technology was able to address the deleterious effects of noise on speech recognition in noise and acceptance of noise levels.

Key Words: auditory training, autism spectrum disorder, remote microphone technology

\begin{abstract}
Abbreviations: ANL = Acceptable Noise Level; APD = auditory processing disorder; APT = auditory processing training; ASD = autism spectrum disorder; BKB-SIN = Bamford-Kowal-Bench Speech-inNoise; CAPDOTS = Central Auditory Processing Disorder Online Therapy System; CELF-5 = Clinical Evaluation of Language Fundamentals-Fifth Edition; CHAPS = Children's Auditory Performance Scale; DIID = dichotic interaural intensity difference; DWT = Dichotic Words Test; LIFE-R = Listening Inventory for Education-Revised; LiSN-S = Listening in Spatialized Noise-Sentence Test; RDDT = Randomized Dichotic Digits Test; RM = remote microphone; SD = standard deviation; SRT = speech reception threshold; TAPS-3 = Test of Auditory Processing Skills-Third Edition
\end{abstract}

\section{INTRODUCTION}

I ndividuals diagnosed with autism spectrum disorder (ASD) exhibit auditory dysfunction and deficits in social communication (Tomchek and Dunn, 2007; Ashburner et al, 2008; American Psychiatric Association, 2013; Schafer et al, 2013; 2016). More specifically, parents of children with ASD report that their children have atypical auditory filtering and processing, difficulty attending to auditory stimuli, distractibility, and dysfunction in noisy environments (Tomchek and Dunn, 2007; Ashburner et al, 2008). In addition, many individuals with ASD display significantly poorer speech recognition in noise, temporal processing, and spatial processing (i.e., binaural integration) than age-matched, typically developing peers (Alcántara et al, 2004; Schafer et al, 2013; Rance et al, 2014). Strategies to enhance the auditory performance of children and young adults with ASD are paramount, given the poor acoustics and high levels of noise found in typical school classrooms paired with the academic difficulties that most children with ASD experience (Cruckley et al, 2011).

Two management approaches to address the auditory deficits in individuals with ASD include the use of remote microphone (RM) technology and the completion of auditory training. RM technology, consisting of a microphone coupled to a transmitter for the primary talker and open-ear receivers for individuals with normal pure-tone hearing, is a highly beneficial strategy that improves speech recognition in noise, auditory comprehension, acceptance of noise, on-task behaviors, teacher- and parent-rated auditory listening behaviors, physiologic stress levels, and self-perceived listening difficulty (Schafer et al, 2013; 2014b; 2016; Rance et al, 2014; 2017).

Although this technology addresses the effects of external noise and poor acoustics, few research studies have investigated strategies to improve auditory processing abilities in individuals with ASD. One strategy that has gained some attention in ASD and other populations is the use of dichotic auditory train- ing (i.e., practice identifying different stimuli presented to the two ears), given that dichotic listening or binaural integration is generally poor in individuals with ASD (Hayashi et al, 1989; Kozou et al, 2018). In one study, three participants with ASD showed improved language and auditory processing following 12 weeks of dichotic listening training (Denman et al, 2015), and more recently, four sessions of dichotic training improved dichotic scores in 125 children and adolescents who had auditory processing deficits, unilateral ear weaknesses, and binaural interaction deficits (Moncrieff et al, 2017). In addition, auditory training with speech-in-noise and dichotic stimuli improved auditory processing abilities in 39 children diagnosed with APD (Loo et al, 2016).

Given the documented benefits of RM technology and the potential benefits of dichotic and speech-based training for individuals diagnosed with ASD, the purpose of the present study was to determine the efficacy and effectiveness of a 12-week auditory processing training (APT) program for children and young adults with ASD. The program consists of computerized dichotic training, oneon-one therapist-directed auditory training, and the use of RM technology at home and in the classroom.

\section{METHODS}

$\mathrm{B}$ efore the candidacy screening, assent was obtained from children aged less than 18 years, and signed consent forms were obtained from parents of those children and adult participants. Candidates for the study were required to pass a pure-tone air conduction hearing screening in each ear at 15 -dB HL for $500-8000 \mathrm{~Hz}$ (audiometer: GSI-51 [Grason Stadler, Eden Prairie, MN]; headphones: TDH-50 [Telephonics, Farmingdale, NY]), have normal middle ear function as measured by Type A tympanograms (Maico MI34; Maico Diagnostics, Eden Prairie, MN), and have normal nonverbal intelligence (i.e., $\geq 70$ ) on the Comprehensive Test of Nonverbal Intelligence-Second Edition (Hammill et al, 2009). 


\section{Participants}

This study was approved by the Institutional Review Board at the University of North Texas. The 15 participants who met the inclusion criteria were high functioning and aged between 7 and 22 years with a formal diagnosis of ASD as his $(n=10)$ or her $(n=5)$ primary disability (Table 1). According to the parent report, the participants were diagnosed with ASD by a licensed specialist in school psychology, a pediatric neurologist, a developmental pediatrician, or a school diagnostician. Participants had no reported otologic history. According to the case history form summarized in Table 2, all participants had major listening difficulties in numerous situations. All participants were righthanded (two participants used both hands for some tasks).

\section{Test Measures and Questionnaires}

The behavioral test measures for this study are detailed in Table 3 and were selected to represent a broad range of auditory processing skills. Participants were asked to complete three, two-day test sessions (three hours each) conducted at baseline (Pretest), immediately after completing the 12-week APT program (Posttest 1), and 12 weeks after the APT program was completed (Posttest 2). Fifteen participants completed the first and second test sessions, and seven participants agreed to complete the third session (participants 1-7). Some participants were unable to complete all test measures because of fatigue, lack of focus, unreliability, or unwillingness to cooperate.

General auditory processing abilities were evaluated with the Test of Auditory Processing Skills-Third Edition (TAPS-3; Martin and Brownell, 2005) and the Clin- ical Evaluation of Language Fundamentals-Fifth Edition (CELF-5; Wiig et al, 2013) Following Directions subtest. Stimuli were presented as live voice by the examiner who was seated approximately three feet from the participant in a quiet room.

Speech recognition in noise and acceptance of noise were assessed with the Bamford-Kowal-Bench Speechin-Noise (BKB-SIN, 2005) and the Acceptable Noise Level (ANL, 2009) tests, respectively, in a sound booth. The BKB-SIN stimuli, which are prerecorded on a compact disc, were presented from a loudspeaker located at $0^{\circ}$ azimuth. This test yields a $50 \%$ correct speech-innoise threshold in $\mathrm{dB}$ SNR (i.e., SNR-50). In addition to the threshold testing, following the 12-week training period, separate lists of the BKB-SIN test were used to assess percent-correct speech recognition in noise with fixed signal levels (-5-dB SNR) with and without the RM technology (Phonak Roger Focus; Sonova USA Incorporated Phonak, Warrenville, IL). In these conditions, the examiner presented the sentence stimuli through the audiometer microphone (i.e., monitored live voice at $65-\mathrm{dBA} / 55-\mathrm{dB} \mathrm{HL}$ ) in the no-technology condition and both the audiometer microphone and the Roger Pen transmitter microphone ( 6 in. from the mouth) in the RM technology condition. The fixed-intensity noise (70-dBA/60-dB HL) was presented from the BKB-SIN compact disc.

The Listening in Spatialized Noise-Sentences Test (LiSN-S) (Cameron and Dillon, 2007) software, administered under circumaural headphones (Sennheiser HD 215), assesses spatial processing abilities in five conditions. The low-cue speech reception threshold (SRT) condition presents the speech and masker at $0^{\circ}$ azimuth, and the high-cue SRT condition presents the speech at $0^{\circ}$ and noise at $\pm 90^{\circ}$ azimuth. The three remaining conditions yield different scores in $\mathrm{dB}$ to assess the

Table 1. Participant Demographic Characteristics

\begin{tabular}{|c|c|c|c|c|c|}
\hline $\begin{array}{l}\text { Subject } \\
\text { No. }\end{array}$ & $\begin{array}{c}\text { Age } \\
\text { (years; months) }\end{array}$ & Gender & Other Disabilities & $\begin{array}{l}\% \text { of CAPDOTS } \\
\text { Completed }\end{array}$ & $\begin{array}{c}\text { Test Sessions } \\
\text { Completed }\end{array}$ \\
\hline$\overline{1}$ & $9 ; 6$ & $\mathrm{~F}$ & ADHD and APD & 80 & 1,2 , and 3 \\
\hline 2 & $21 ; 9$ & M & ADHD & 67 & 1,2 , and 3 \\
\hline 3 & $7 ; 5$ & M & ADHD & 91 & 1,2 , and 3 \\
\hline 4 & $7 ; 11$ & M & ADHD, language disability, and anxiety disability & 51 & 1,2 , and 3 \\
\hline 5 & $14 ; 7$ & M & ADHD and SLI & 100 & 1,2 , and 3 \\
\hline 6 & $10 ; 3$ & M & Language disability & 51.1 & 1,2 , and 3 \\
\hline 7 & $12 ; 0$ & $\mathrm{~F}$ & SLI and language disability & 89 & 1,2 , and 3 \\
\hline 8 & $20 ; 6$ & M & ADHD, learning disability, and APD & 88 & 1 and 2 \\
\hline 9 & $16 ; 4$ & $\mathrm{~F}$ & Anxiety disabiity & $100 / 98.1$ & 1 and 2 \\
\hline 10 & $21 ; 8$ & $\mathrm{~F}$ & ADHD and anxiety disability & $100 / 73.1$ & 1 and 2 \\
\hline 11 & $21 ; 5$ & $\mathrm{~F}$ & ADHD & $100 / 73.1$ & 1 and 2 \\
\hline 12 & $10 ; 2$ & M & Language disability & $100 / 71.1$ & 1 and 2 \\
\hline 13 & $15 ; 10$ & M & Did not complete form & $100 / 31.1$ & 1 and 2 \\
\hline 14 & $9 ; 5$ & M & Did not complete form & $100 / 88.9$ & 1 and 2 \\
\hline 15 & $15 ; 7$ & M & Language disability & 100 & 1 and 2 \\
\hline
\end{tabular}

Note: Some participants repeated the CAPDOTS program within the 12-week training period. ADHD = attention-deficit hyperactivity disorder; $\mathrm{APD}=$ auditory processing disorder; SLI = specific language impairment. 
Table 2. Parent- or Participant-Reported Listening Difficulties

\begin{tabular}{|c|c|}
\hline & Participant Number \\
\hline \multicolumn{2}{|l|}{ Listening situation } \\
\hline In most situations & $1,5,7,9,10,11$, and 15 \\
\hline In small groups & $5,7,9$, and 15 \\
\hline In large groups & $3,4,5,6,8,9,10,12$, and 15 \\
\hline In the classroom & $4,5,6,7,8,9,10$, and 15 \\
\hline At parties & $3,4,5,8,9,10,11,12$, and 15 \\
\hline In restaurants & $3,4,5,7,8,9,10,15$ \\
\hline $\begin{array}{l}\text { In other social } \\
\text { situations }\end{array}$ & $3,9,10,11,12$, and 15 \\
\hline \multicolumn{2}{|l|}{ Listening problems } \\
\hline Paying attention & $1,2,3,4,5,6,7,8,10$, and 15 \\
\hline Easily distracted & $\begin{array}{l}1,2,3,4,5,6,7,8,10,11,12 \text {, and } \\
15\end{array}$ \\
\hline $\begin{array}{l}\text { Confused in noisy } \\
\text { situations }\end{array}$ & $1,3,4,5,6,7,8,10,11$, and 12 \\
\hline $\begin{array}{l}\text { Difficulty following } \\
\text { directions }\end{array}$ & $1,3,5,6,7,8,9,11$, and 15 \\
\hline $\begin{array}{l}\text { Sensitive to loud } \\
\text { sounds }\end{array}$ & $1,2,3,4,5,6,7,8,10,11$, and 12 \\
\hline $\begin{array}{l}\text { Easily upset by new } \\
\text { situations }\end{array}$ & $1,3,5,7,9,10$, and 11 \\
\hline Difficulty sitting still & $3,4,5,8,9,10,11$, and 12 \\
\hline Impulsive & $2,4,5,8,9,10$, and 12 \\
\hline Often daydreams & $1,2,3,5,7,9,10,11,12$, and 15 \\
\hline $\begin{array}{l}\text { Often asks for } \\
\text { repetition }\end{array}$ & $1,3,5,6,7,9,10$, and 11 \\
\hline $\begin{array}{l}\text { Prefers to play/do } \\
\text { activities alone }\end{array}$ & $3,5,7,8,10,11$, and 12 \\
\hline $\begin{array}{l}\text { Yelling or rowdy } \\
\text { behavior }\end{array}$ & 5,6 , and 9 \\
\hline Shy and anxious & $3,5,6,7,9,10$, and 15 \\
\hline Lacks self confidence & $5,7,9,10,11,12$, and 15 \\
\hline $\begin{array}{l}\text { Does not complete } \\
\text { assignments }\end{array}$ & $1,5,7,8$, and 10 \\
\hline Easily frustrated & $1,2,3,4,5,6,7,8,9,10,11$, and 15 \\
\hline
\end{tabular}

potential benefit of (a) same versus different talkers for the stimulus and masker presented at $0^{\circ}$ azimuth (talker advantage), (b) same talkers with noise at $0^{\circ}$ versus $\pm 90^{\circ}$ azimuth (spatial advantage), and (c) same stimulus and masker at $0^{\circ}$ versus different stimulus and masker with speech at $0^{\circ}$ and the masker at $\pm 90^{\circ}$ azimuth (total advantage). Binaural integration was assessed with the Dichotic Words Test (DWT) and Randomized Dichotic Digits Test (RDDT), which were administered under circumaural headphones (Sennheiser HD 215) using the Audia Dichotic software (Dichotics, Inc., n.d.).

Participants who were able to reliably complete questionnaires were asked to complete the Listening Inventory for Education-Revised (LIFE-R; Anderson et al, 2011). Parents of children ( $\leq 14$ years) were asked to complete the Sensory Profile 2 (Dunn, 2014), and classroom teachers of the children ( $\leq 18$ years) were asked to complete the teacher version of the LIFE questionnaire and the Children's Auditory Performance Scale (CHAPS; Smoski et al, 1998).

\section{Auditory Processing Training Program}

The APT program required participants to complete a one-hour training session three times/week for 12 weeks in the laboratory and to use RM technology at home and school. Each training consisted of 30 minutes of an active, web-based dichotic integration listening training known as the Central Auditory Processing Disorder Online Therapy System (CAPDOTS-Integrated, 2018) and 30 minutes of one-on-one, clinician-developed, auditory training in a quiet room.

CAPDOTS is a dichotic listening training program that uses interaural and adaptive lead-lag timing differences to improve binaural integration skills of different speech stimuli (words, numbers, and syllables). Its goal is similar to the dichotic interaural intensity difference (DIID) training (Weihing and Musiek, 2014) but differs from DIID in approach. DIID uses interaural intensity or loudness differences. However, with CAPDOTS, the dichotic stimuli are equal in intensity in each ear but only differ in the timing of the presentation stimuli. CAPDOTS is a free-recall training program whereby the participant repeats what is heard in both ears and is not required to repeat a specific side (left or right) first, as is the case in directed-ear exercises. Directed-ear exercises require higher levels of cognitive control and executive function (Hugdahl et al, 2009). As with all free-recall exercises, there is no need to identify a dominant ear. With this in mind, CAPDOTS exercises are balanced with half of the items presented on the left side first, followed by the right side after a prescribed lag time. The other half of the items are presented to the right side, followed by the left side after a prescribed lag time. Again, the participant's order of response was not a scoring factor. Handedness, also, is not a necessary consideration during training.

A graduate student serving as a test assistant was seated next to the participant to record all correct responses. CAPDOTS was administered via a laptop computer and supra-aural headphones (Sony ZX310; Sony Corporation of America, New York, NY). The percentage of CAPDOTS completion is shown in Table 1. Participants who have two percentages completed the program and began the program a second time.

The 30 minutes of one-on-one adaptive training activities were individualized for each participant based on Pretest functioning levels on the TAPS-3 and CELF-5. In addition to examining overall subtest scores for each participants, the speech-language pathologist noted where breakdowns started to occur (e.g., repeating 
Table 3. Detailed Descriptions of Behavioral Test Measures

\begin{tabular}{|c|c|c|}
\hline Test Name & General Description & Test Detail \\
\hline TAPS-3 & $\begin{array}{l}\text { Hierarchy of Aud. processing skills needed for } \\
\text { development, use, and understanding of } \\
\text { language in academic and everyday settings }\end{array}$ & $\begin{array}{l}\text { Word discrimination, Phon. segmentation, Phon. } \\
\text { blending, numbers forward and reversed, word } \\
\text { memory, sentence memory, Aud. } \\
\text { comprehension, and Aud. reasoning }\end{array}$ \\
\hline CELF-5 & $\begin{array}{l}\text { Examines understanding of spoken directions, } \\
\text { recall of information, and recognition of pictured } \\
\text { objects }\end{array}$ & Following Directions subtest \\
\hline $\begin{array}{l}\text { BKB-SIN test-two-list } \\
\text { pairs }\end{array}$ & $\begin{array}{l}\text { Estimates the SNR necessary for the listener to } \\
\text { repeat } 50 \% \text { of key words in multitalker babble }\end{array}$ & $\begin{array}{l}\text { Determined dB SNR with loudspeakers at } 0^{\circ} \text {; also } \\
\text { tested live voice-5 } \mathrm{dB} \text { SNR (speech } 60 / \text { noise } \\
65 \text { ) with and without RM technology to yield \% } \\
\text { correct. }\end{array}$ \\
\hline ANL test & $\begin{array}{l}\text { Quantifies SNR listener is willing to accept or "put } \\
\text { up with" for a long period of time }\end{array}$ & $\begin{array}{l}\text { Tested with and without RM technology, male talker } \\
\text { at } 0^{\circ} \text { azimuth, noise at } 180^{\circ} \text {, and ANL repeated } \\
\text { twice and averaged }\end{array}$ \\
\hline LiSN-S & $\begin{array}{l}\text { Evaluates the listener's ability to separate stimuli } \\
\text { differing in space }\left( \pm 0^{\circ} \text { azimuth vs. } \pm 90^{\circ} \text { azimuth) }\right. \\
\text { and vocal quality (same vs. different voices) }\end{array}$ & $\begin{array}{l}\text { Low-cue SRT: no spatial/vocal cues available; high- } \\
\text { cue SRT: both vocal/spatial cues available; talker } \\
\text { Adv: use of different vocal characteristics; spatial } \\
\text { Adv: use differences in the physical location; and } \\
\text { total Adv: use of talker and spatial Adv cues }\end{array}$ \\
\hline DWT and RDDT & $\begin{array}{l}\text { Assess binaural integration or significant ear } \\
\text { differences for dichotic word or digit stimuli. }\end{array}$ & $\begin{array}{l}\text { Stimuli include } 4 \text { lists of } 25 \text { word pairs and } 2 \text { lists of } \\
54 \text { sets of 1-, 2-, and } 3 \text {-digit pairs. Stimuli } \\
\text { presented simultaneously to ears; listener asked } \\
\text { to repeat stimuli free recall }\end{array}$ \\
\hline Child Sensory Profile 2 & $\begin{array}{l}\text { Parent ranks child's sensory processing patterns on } \\
\text { a scale of } 5 \text { (almost always) to } 1 \text { (almost never) in } \\
\text { the context of everyday situations }\end{array}$ & $\begin{array}{l}\text { Ratings analyzed for audition, social-emotional, } \\
\text { attention, seeking/seeker, avoiding/avoider, } \\
\text { sensitivity/sensor, and registration/bystander }\end{array}$ \\
\hline $\begin{array}{l}\text { LIFE-R_-student and } \\
\text { teacher version }\end{array}$ & $\begin{array}{l}\text { Teacher or student rates his or her own classroom } \\
\text { listening abilities as compared with peers on a } \\
\text { scale of } 5 \text { (always easy) to } 1 \text { (always difficult) }\end{array}$ & $\begin{array}{l}\text { No listening challenges }=75 \\
\text { Occasional listening challenges }=60 \\
\text { Sometimes challenged }=45 \\
\text { Often or regularly has challenges }=30 \\
\text { Almost always challenged }=15\end{array}$ \\
\hline CHAPS & $\begin{array}{l}\text { Teacher rates listening behaviors in the classroom } \\
\text { relative to peers on a scale from }+1 \text { (less } \\
\text { difficulty) to }-5 \text { (cannot function at all) }\end{array}$ & $\begin{array}{l}\text { Rating averaged across conditions to determine if } \\
\text { child is at-risk for academic issues: noise, quiet, } \\
\text { ideal conditions, multiple inputs, auditory } \\
\text { memory sequencing, auditory attention span }\end{array}$ \\
\hline
\end{tabular}

$\overline{\mathrm{Adv}}=$ advantage; Aud. = auditory; Phon. = phonological.

sentences with three major components) to determine appropriate tasks for each participant. Training tasks included (a) following directions (e.g., "point to the boy with brown hair"), (b) word and sentence repetition (e.g., repeat three word set: "row, baby, and light"), and (c) auditory comprehension (e.g., three components: "Sam/went to the park/to play on the slide."; "Where the boy did he go?"; "What was the boy's name who went?"; and "What did he play on?"). Training stimuli were presented in quiet and increasing levels of background noise (i.e., quiet room, $45,50,55$, and $60 \mathrm{dBA}$ ). The noise level was increased by one step each time the task was mastered with $80 \%$ accuracy. Linguistic complexity was increased by $5 \mathrm{~dB}$ once a particular level was mastered at each of the four background noise levels. The overall goal was to achieve maximum linguistic functioning at noise levels experienced in everyday listening situations.

After the first testing session, the participants were fit with bilateral Roger Focus receivers with a small dome used in conjunction with a Roger Pen transmitter. Appropriate volume settings on the receivers were determined using the Desired Sensation Level v5 prescriptive targets for 15-dB HL hearing thresholds as measured with the Audioscan Verifit 2 (Audioscan, Dorchester, Ontario) (Scollie et al, 2005; Schafer et al, 2014a). During the 12-week training period, the participants were asked to use the RM technology at home and at school during direct instruction from the teacher. It is important to note that the investigators could not determine exact hours of RM technology use per day; however, parents and participants confirmed that the system was used on a regular basis.

\section{RESULTS}

verage raw scores across TAPS-3 subtests are

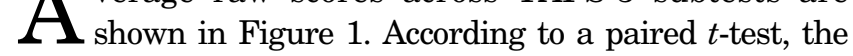
average raw scores significantly improved on six subtests. However, average raw scores on the CELF-5 




Figure 1. Average raw scores on the TAPS pre- and post-APT program $(\mathrm{N}=15)$. Data were analyzed with a paired $t$-test; statistical results are provided. Vertical lines represent one SD.

Following Directions subtest were not significantly different between Pretest ( $M=20.1$; standard deviation $[\mathrm{SD}]=8.8)$ and Posttest $1[M=22.0 ; \mathrm{SD}=6.9$; $t_{(14)}=-1.7, p=0.06$, one-tailed].

Average BKB-SIN thresholds $(\mathrm{n}=15)$ were not significantly different between Pretest $(M=0.76 \mathrm{~dB}$; $\mathrm{SD}=3.0)$ and Posttest $1(M=-0.14 \mathrm{~dB}$; SD $=$ 2.2) $\left[t_{(14)}=-0.14, p=0.44\right]$. Similarly, the average ANLs $(\mathrm{n}=14)$ were not significantly different at Pretest $(M=4.3 \mathrm{~dB} ; \mathrm{SD}=9.0)$ and Posttest $1(M=4.7 \mathrm{~dB}$; $\mathrm{SD}=6.7)\left[t_{(14)}=-0.14, p=0.44\right]$.

However, when comparing the performance in the no-technology condition $(M=63.3 \%$; SD $=28.5)$ with the RM technology condition $(M=99.6 \%$; $\mathrm{SD}=0.93)$, a paired $t$-test $(\mathrm{n}=11)$ showed a significant average improvement $\left[t_{(11)}=-4.1, p=0.001\right]$ in percent-correct speech recognition in noise scores. Likewise, participants $(n=8)$ showed a significantly lower (better) ANL when using the RM system $(M=0.69$; SD $=$ 7.0) as compared with the condition with no-RM system $(M=7.4 ; \mathrm{SD}=7.4)\left[t_{(8)}=2.4, p=0.02\right]$.

The average performance $(\mathrm{N}=15)$ and data analyses for the LiSN-S are shown in Figure 2. For the SRT conditions, significantly better performance was found after training in the high-cue condition (i.e., lower thresholds), but not the low-cue condition. For the advantage conditions, no difference was detected across test time, but significant differences were found across all three conditions (total $>$ spatial $>$ talker). No significant interaction effects were found for either analysis.

Average performance and analyses for the DWT and RDDT are shown in Figures 3 and 4, respectively, where data were categorized according to the dominant (i.e., higher score) and nondominant ear (Moncreiff, 2015).
For the DWT, post hoc analyses suggested that Posttest 1 scores were significantly higher than Pretest scores, but the significant improvements occurred only in the nondominant ear. Interaural asymmetry (ear differences) significantly decreased from Pretest to Posttest 1 (Figure 5). For the RDDT (Table 4), all Posttest 1 scores were significantly better than the Pretest score for the nondominant ear. Interaural asymmetry significantly decreased from Pretest to Posttest 1 for the two- and three-pair digits.

\section{Questionnaires}

On the participant LIFE-R questionnaire $(n=10)$, the average sum of the ratings for the Pretest was 50.2 (SD = 16.7) and for Posttest 1 was 59.3 (SD = 7.4). According to a Wilcoxon signed-rank test, the participants perceived significant improvements in classroom listening after training and the use of the RM technology $(z=-1.5$, $p=0.05)$. Average ratings on the Sensory Profile $2(\mathrm{n}=$ 10) are shown in Figure 6; significant results were found in several conditions. Despite multiple inquiries, the response rate for the LIFE-R and the CHAPS teacher questionnaires was poor, and as a result, these results do not represent the entire sample. The results of the few questionnaires that were returned are provided in Table 5. Overall, most participants were reported to have difficulties listening before the study, and for those who completed the posttest questionnaires, modest improvements in listening ability were documented.

\section{Posttest 2 Results}

The analyses for the seven participants (1-7 in Table 1 ), aged 7 years 5 months to 21 years 9 months, 


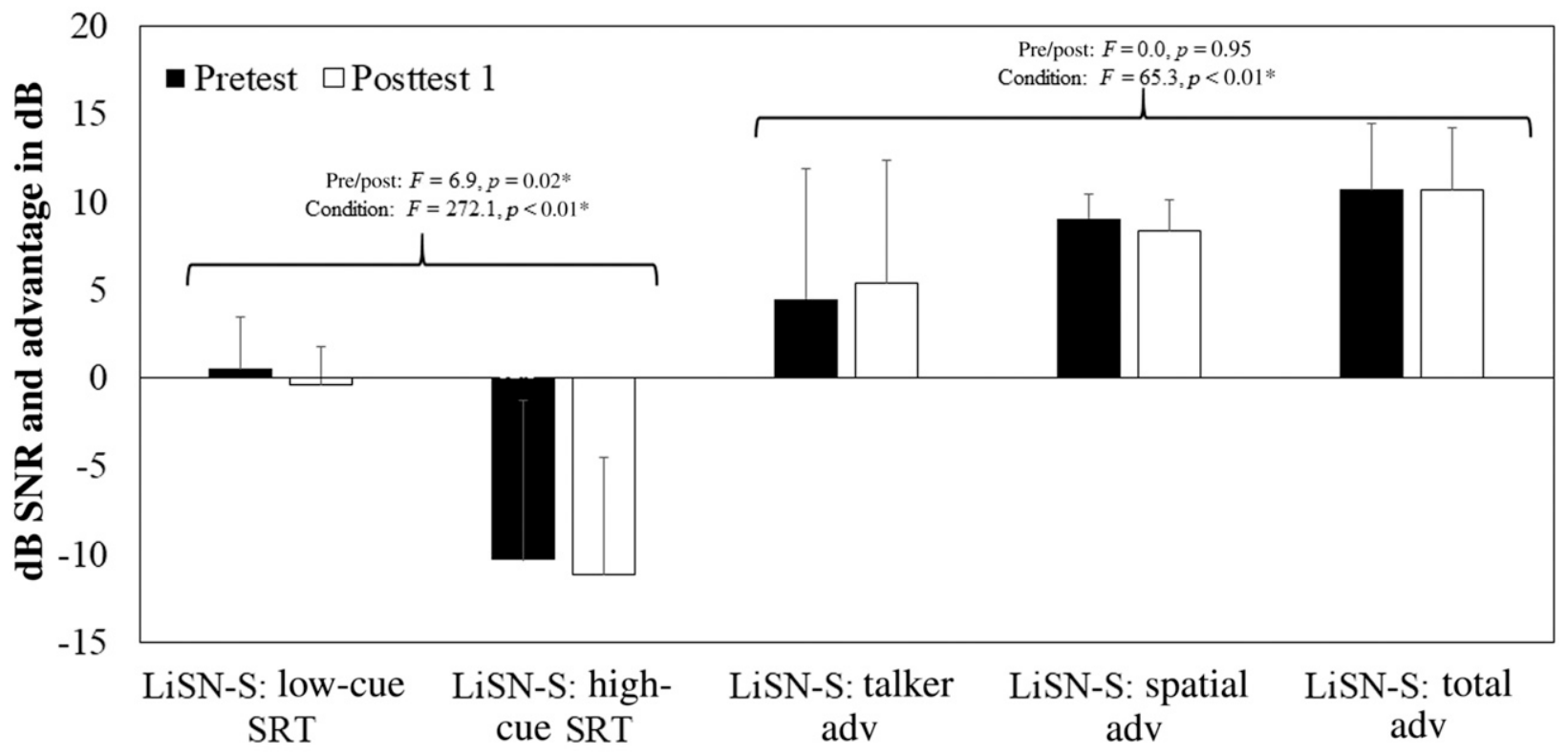

\section{Test: Condition}

Figure 2. Results on the LiSN-S for the SRT conditions (in dB SNR where lower is better) and the advantage conditions (dB where higher is better). LiSN-S data were analyzed with two separate, two-factor repeated measures analysis of variance with a Greenhouse-Geisser correction. Adv = advantage; vertical lines represent one SD.

who completed a third test session (12-week training) are provided in Table 6. Overall, the significant performance improvements measured for most tests from the Pretest to the Posttest 1 sessions were maintained in the Posttest 2 session.

\section{DISCUSSION}

$\Gamma$ he primary goal of this study was to determine the efficacy and effectiveness of the 12-week APT program for enhancing general auditory processing skills

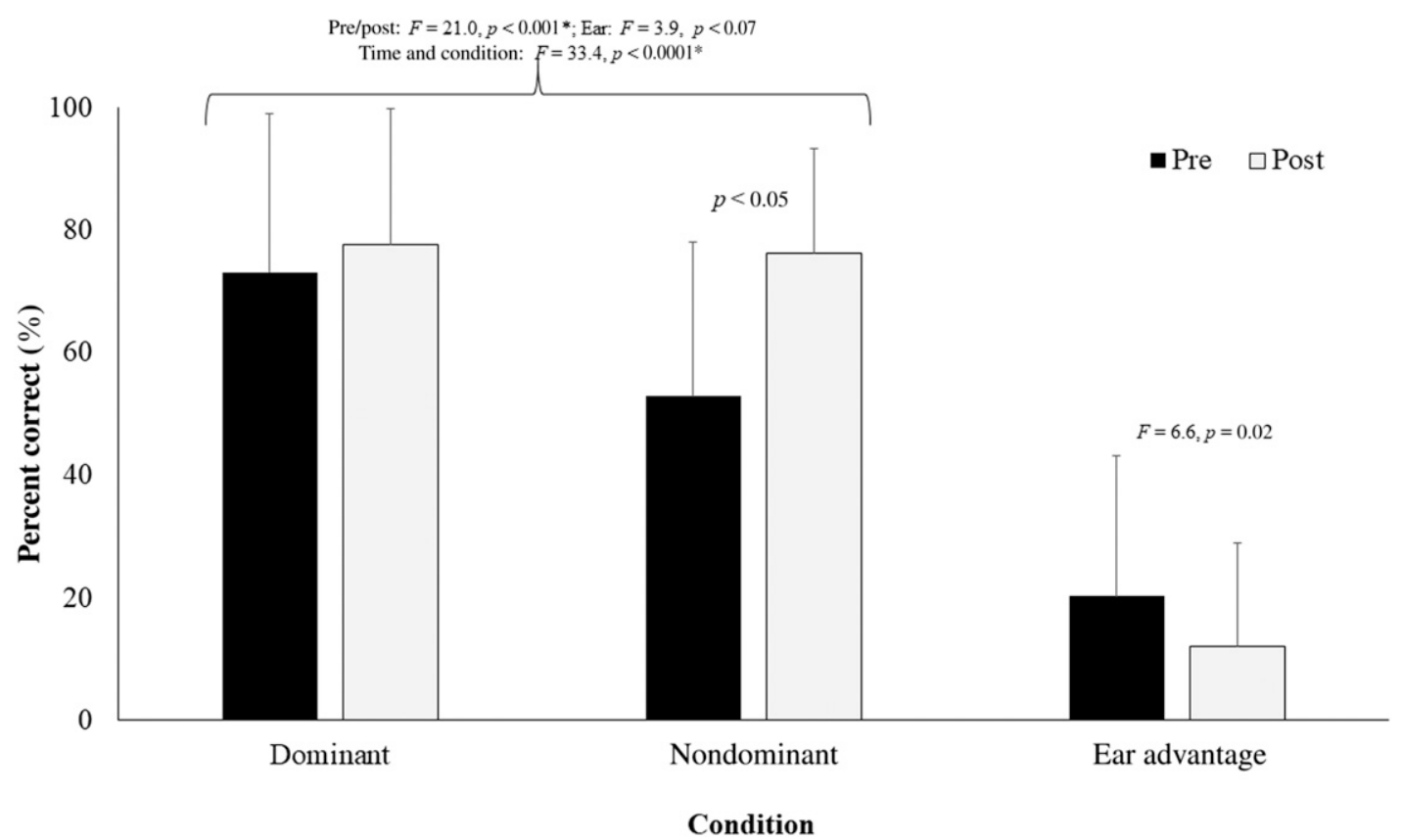

Figure 3. Average percent-correct scores on the DWT $(\mathrm{N}=15)$. Because of expected performance differences (Moncreiff and Wilson, 2009), data were analyzed with a two-factor repeated measures analysis of variance with a Greenhouse-Geisser correction. Vertical lines represent one $\mathrm{SD}$. 


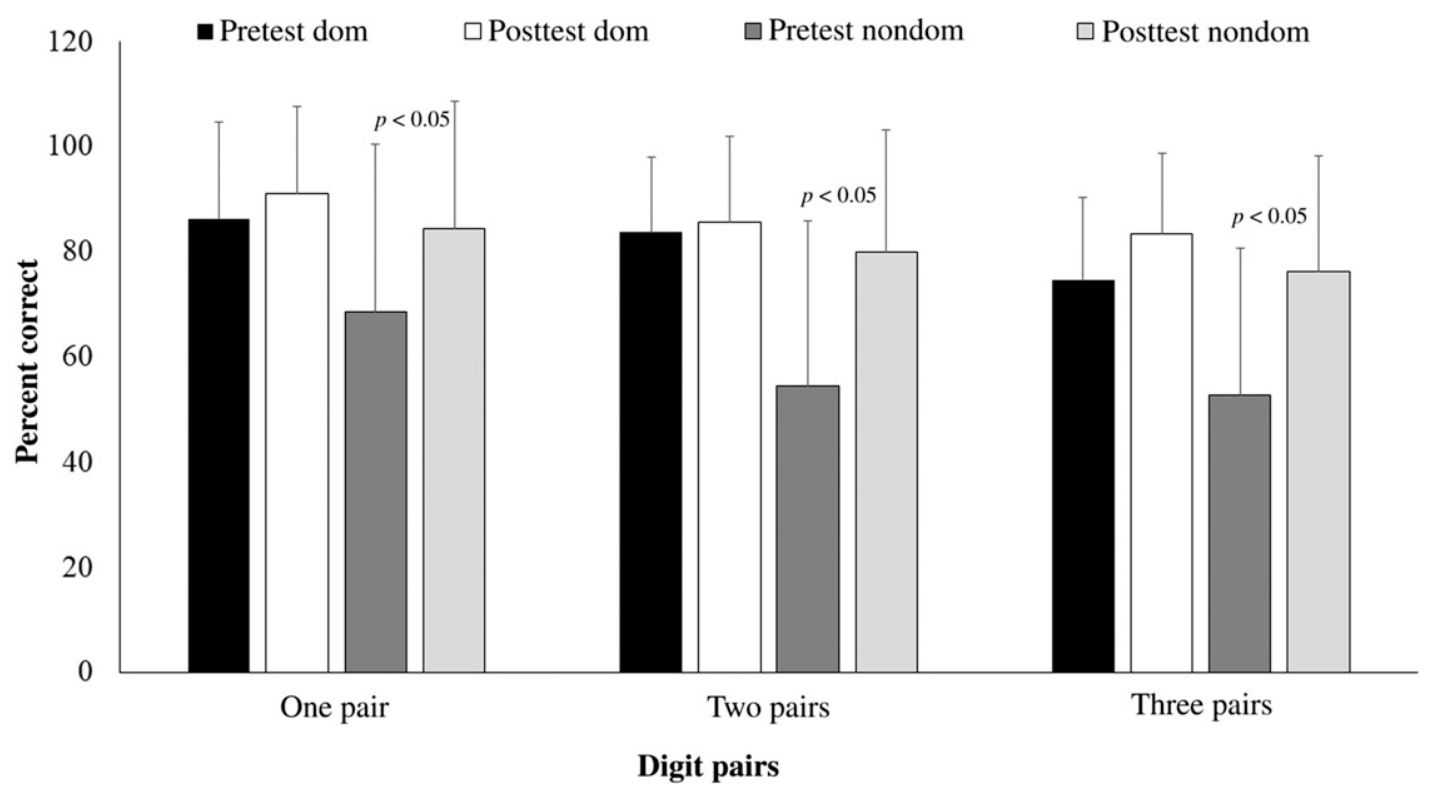

Figure 4. Average percent-correct scores on the RDDT $(\mathrm{N}=15)$. Vertical lines represent one SD. Dom = dominant ear; Non-Dom = Nondominant ear.

in individuals with ASD. Following the completion of the APT program, on average, the 15 participants exhibited behavioral improvements in multiple areas, including phonological segmentation and blending (TAPS-3), number and word memory (TAPS-3), auditory reasoning (TAPS-3), and binaural integration of words and digit spans (DWT and RDDT). In particular, the abnormal interaural asymmetry on dichotic testing was significantly reduced. When the RM technology was in use, percent-correct speech recognition in noise and acceptance of background noise levels significantly improved on the BKB-SIN and ANL tests, respectively. However, results on these tests did not show improvement after training when the RM technology was not in use. The ability to hear a speaker in speech competition showed significant improvement after training as measured by the LiSN-S high-cue condition, although improvement was not seen on the advantage conditions. When examining the effectiveness of the training, participant, parent, and/or teacher questionnaires confirmed improvements in auditory processing (Sensory Profile 2), attentional responses associated

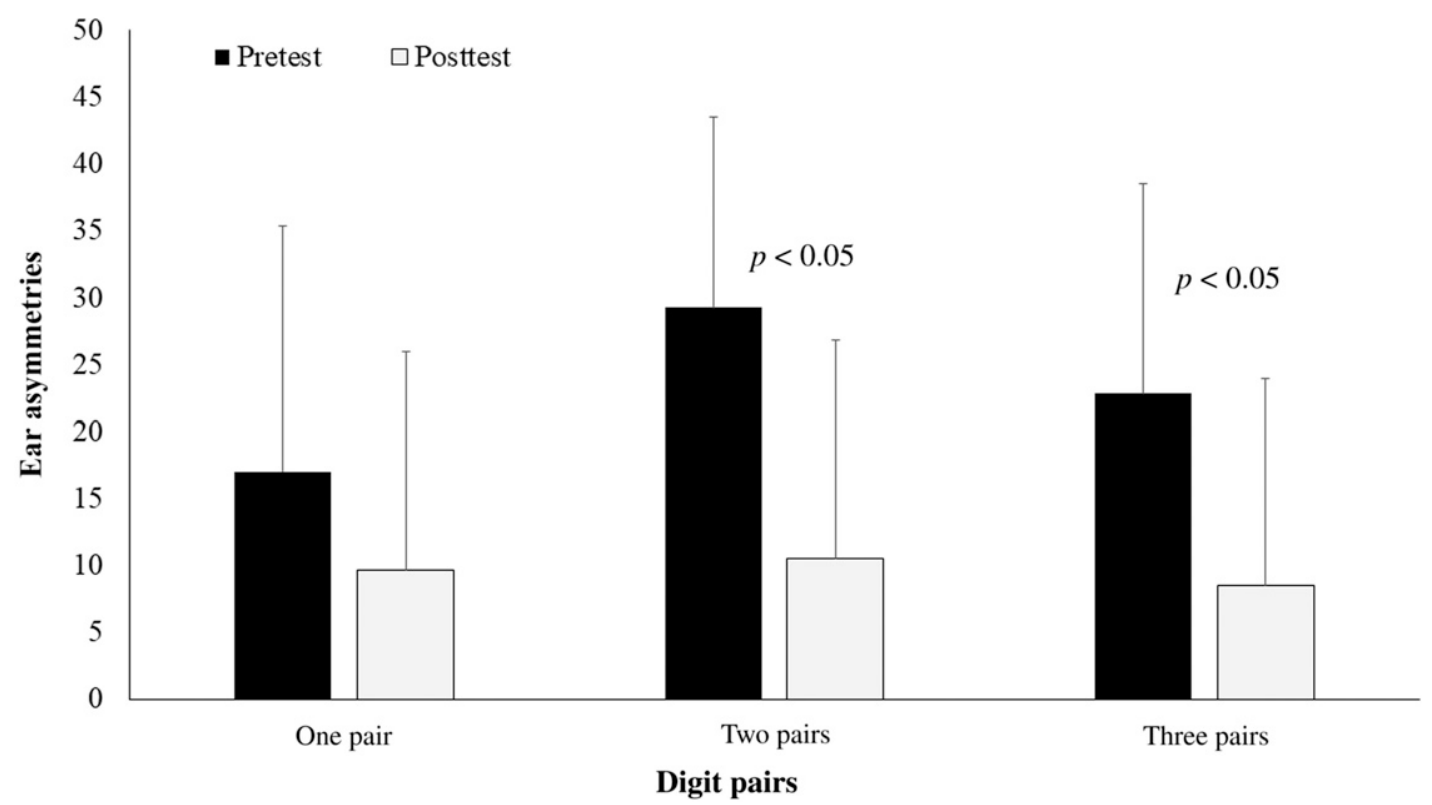

Figure 5. Average interaural asymmetry calculations on the RDDT. Vertical lines represent one SD. 
Table 4. Statistical Analyses of the RDDT Data

\begin{tabular}{|c|c|c|c|c|c|}
\hline Test & Main Effect & $\mathrm{df}$ & F-Statistic & $p$-Value & Interpretation and Post Hoc Results \\
\hline \multirow[t]{3}{*}{ One pair } & Time & 1,60 & 6.6 & $0.02^{*}$ & Posttest $1>$ Pretest \\
\hline & Ear & 1,60 & 7.1 & $0.02^{*}$ & Dominant $>$ nondominant \\
\hline & Interaction & 1,60 & 9.8 & $0.01^{*}$ & All conditions $>$ Pretest for nondominant ear \\
\hline \multirow[t]{3}{*}{ Two pair } & Time & 1,60 & 10.8 & $0.005^{*}$ & Posttest $1>$ Pretest \\
\hline & Ear & 1,60 & 14.8 & $0.001^{*}$ & Dominant $>$ nondominant \\
\hline & Interaction & 1,60 & 14.2 & $0.002^{*}$ & All conditions $>$ Pretest for nondominant ear \\
\hline \multirow[t]{3}{*}{ Three pair } & Time & 1,60 & 15.8 & $0.001^{*}$ & Posttest $1>$ Pretest \\
\hline & Ear & 1,60 & 13.1 & $0.003^{*}$ & Dominant $>$ nondominant \\
\hline & Interaction & 1,60 & 6.8 & $0.02^{*}$ & All conditions $>$ Pretest for nondominant ear \\
\hline \multirow[t]{3}{*}{ Ear advantage } & Time & 1,90 & 19.6 & $0.002^{*}$ & Posttest $1<$ Pretest \\
\hline & Digit pair & 1,90 & 3.0 & 0.09 & No advantage differences among digit pairs \\
\hline & Interaction & 1,90 & 2.2 & 0.15 & No interaction \\
\hline
\end{tabular}

Note: Data were analyzed with a two-factor repeated measures analysis of variance with a Greenhouse-Geisser correction; post hoc comparisons were conducted with the Tukey-Kramer multiple comparisons test. $\mathrm{N}=15$.

*Statistically significant.

with sensory processing (Sensory Profile 2), the detection of sensory input (Sensory Profile 2), and reduced listening challenges in the classroom across various listening situations (LIFE-R and CHAPS).

When considering the specific areas of improvement and areas that did not improve, several noteworthy findings were considered. First, when considering all of the areas that improved on the TAPS-3 (phonological segmentation and blending; number and word memory; and auditory reasoning) and the binaural integration tasks (DWT and RDDT), it is evident that each of these tests and subtests required verbal and auditory working memory for various stimuli, areas in which those with ASD struggle when compared with neurotypical peers (Macizo et al, 2016; Wang et al, 2017; Vogan et al, 2018). As a result, completion of the APT program addressed a significant deficit area for children with ASD. Given the wide range of stimuli used across the two training components of the APT program, the authors hypothesize that both aspects of the program, the one-on-one therapy and the dichotic listening training, resulted in the improved working memory on the various tasks. A similar type of training focused on auditory, visual, and visual-spatial working memory has also been successful for individuals with ASD (Weckstein et al, 2017).

Second, the Pretest and Posttest 1 scores on the DWT and RDDT highlight the substantial ear differences found for most participants, particularly on the RDDT. In addition, there is a possibility of age effects on these tests. On average, the eight older participants $(>12$ years) had higher scores of $79 \%(\mathrm{SD}=10)$ and $64 \%$

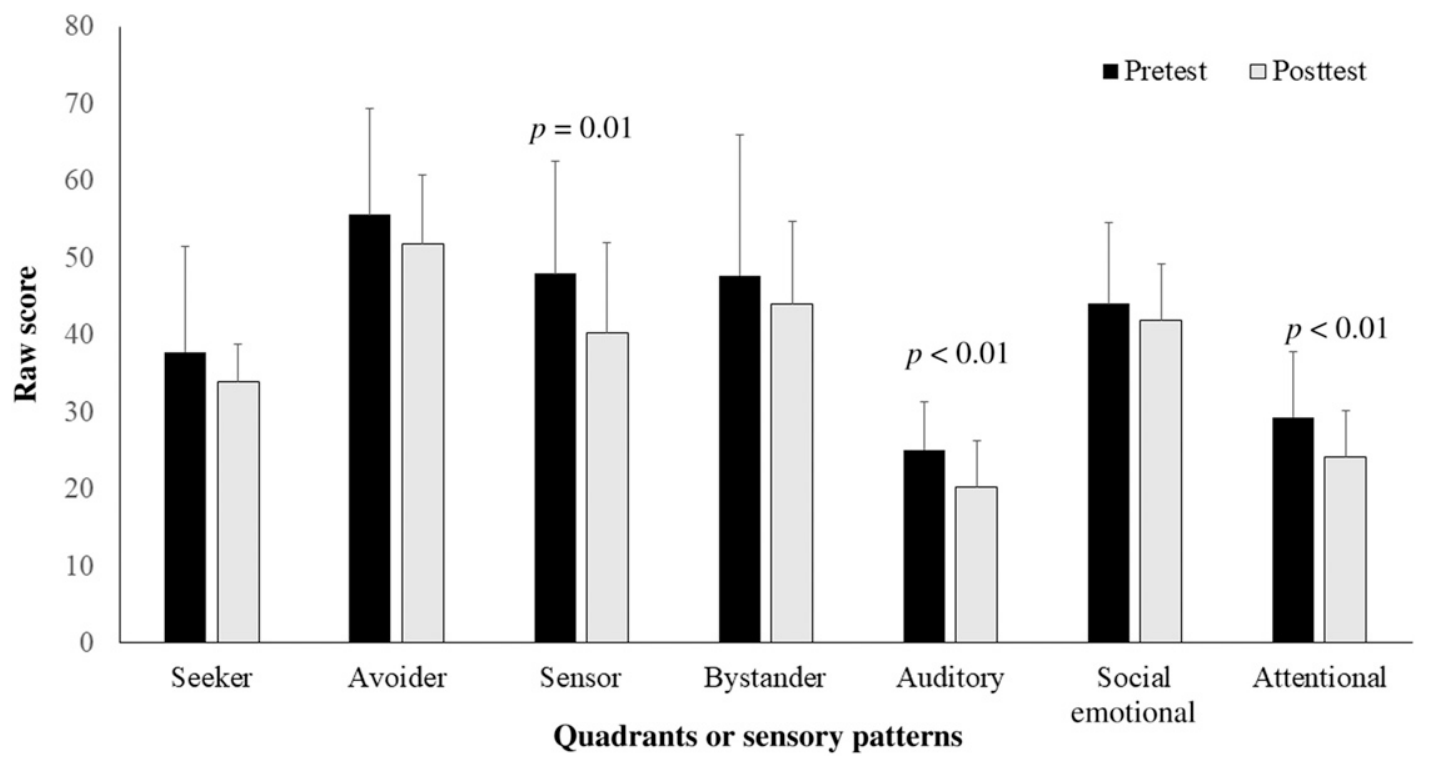

Figure 6. Average raw scores on the Sensory Profile 2 questionnaire. The attention ratings relate to the child's attentional responses associated with sensory processing. Data were analyzed with the Wilcoxon signed-rank test. Vertical lines represent one SD. 
Table 5. Teacher Ratings on LIFE-R and CHAPS Questionnaires

\begin{tabular}{llcl}
\hline Participant & \multicolumn{3}{c}{ Pretest $\begin{array}{c}\text { Posttest } 1 \\
\text { LIFE-R }\end{array}$} \\
\hline 1 & 43 & 57 & \multicolumn{1}{c}{ Sometimes experiences listening challenges to occasional listening challenges at posttest } \\
3 & 61 & 75 & Occasional listening challenges to no listening challenges or very rare at posttest \\
4 & 47 & 55 & Sometimes experiences listening challenges to occasional listening challenges at posttest \\
5 & 20 & $*$ & Almost always has listening challenges at pretest \\
6 & $*$ & 58 & Occasional listening challenges at posttest \\
7 & 18 & $*$ & Almost always has listening challenges at pretest \\
14 & 47 & $*$ & Sometimes experiences listening challenges at pretest. \\
& & CHAPS & \\
1 & -2.47 & -0.47 & At risk to normal \\
3 & -0.14 & 0 & Normal to normal \\
4 & -2.2 & -0.5 & At risk to normal \\
5 & -4.27 & -1.05 & At risk to at risk \\
6 & $*$ & -0.83 & * to normal \\
7 & -4.03 & -3.72 & At risk to at risk \\
12 & -1.14 & -1.16 & At risk to at risk \\
13 & -1.6 & $*$ & At risk to * \\
14 & -1.8 & $*$ & At risk to * \\
15 & -2.38 & $*$ & At risk to *
\end{tabular}

*Indicates that the teacher did not return the questionnaire. Higher ratings on the LIFE-R indicate fewer listening challenges. Lower ratings (more negative) on the CHAPS indicate greater listening difficulty.

$(\mathrm{SD}=20)$ for the dominant and nondominant ears, respectively, than the dominant and nondominant scores of $66 \%(\mathrm{SD}=21)$ and $41 \%(\mathrm{SD}=32)$, respectively, for the younger participants. Similarly, when examining the average two-pair digit data, the eight older participants $(>12$ years) had higher scores of $89 \%(\mathrm{SD}=18)$ and $71 \%(\mathrm{SD}=24)$ for the dominant and nondominant ears, respectively, than the dominant and nondominant scores of $77 \%(\mathrm{SD}=16)$ and $35 \%(\mathrm{SD}=30)$, respectively, for the younger participants.

Most notable, however, is that following training, all participants improved their nondominant ear scores on the DWT, and all but one participant (who had 97\% correct on the Pretest) improved their scores on the two-pair digits. In addition, in the dominant ear, seven participants improved their DWT scores, and eight participants showed improved performance on the two-pair digits. Age did not appear to be a factor in the presence or absence of improvements in the dominant ear. More specifically, for the seven participants who had abnormal DWT performance at Pretest, four showed typical performance after training, and abnormal interaural asymmetries were eliminated in two additional participants. For the 11 subjects with abnormal RDDT performance at Pretest, four had typical performance after training. Two additional participants who had unilateral weakness and poor scores bilaterally no longer showed unilateral weakness after training. Given the substantial improvements, it is evident that the CAPDOTS training directly addressed some of the binaural integration weaknesses seen on the dichotic tests. Similar training has been successful in children diagnosed with auditory processing disorders (Moncrieff et al, 2017).

Third, although the response rate was poor for some of the questionnaires, particularly those from the teachers, at least two questionnaires for each participant documented listening difficulties in various everyday situations. In addition, participant listening difficulties were documented on the case history form (summarized in Table 2). Following training, at least one questionnaire for each participant documented decreased listening difficulty in various listening situations inside or outside of the classroom. The most complete Pretest and Posttest datasets were obtained for the participant LIFE-R $(\mathrm{n}=10)$ and the parent Sensory Profile $(\mathrm{n}=10)$. Results of these questionnaires suggested improvements for listening in classroom situations, processing of general sensory input, and attentional behaviors (e.g., eye contact and paying attention). Given the poor return rate from the teacher questionnaires, caution must be used when interpreting these limited results (Table 5).

In contrast to the aforementioned tests and questionnaire results, after the APT program, no group improvements in spatial processing were measured on the LiSN-S test, likely because of normal Pretest scores, and no group improvements were measured for speech recognition in the presence of noise on the BKB-SIN. Although the APT program did not significantly improve speech recognition in noise performance on the BKB-SIN, descriptive analysis of the individual data provides some insights into the speech recognition deficits of the participants. First, when comparing individual 
Table 6. Results of Repeated Measures ANOVA from Participants Who Completed Three Test Sessions

\begin{tabular}{|c|c|c|c|c|c|}
\hline Test & Subtest & df & F-Statistic & $p$-Value & Interpretation and Post Hoc Results \\
\hline \multirow[t]{9}{*}{ TAPS-3 } & Word discrimination & 2,21 & 0.64 & 0.54 & No differences across three test sessions \\
\hline & Phonol segmentation & 2,21 & 1.5 & 0.26 & No differences across three test sessions \\
\hline & Num Mem forward & 2,21 & 6.8 & $0.01^{*}$ & Posttest $2>$ Pretest; Posttest $1=$ Posttest 2 \\
\hline & Num Mem reversed & 2,21 & 2.7 & 0.12 & No differences across three test sessions \\
\hline & Word memory & 2,21 & 2.2 & 0.15 & No differences across three test sessions \\
\hline & Sentence memory & 2,21 & 0.76 & 0.50 & No differences across three test sessions \\
\hline & Auditory comp & 2,21 & 0.01 & 0.99 & No differences across three test sessions \\
\hline & Auditory reasoning & 2,21 & 7.3 & $0.009^{*}$ & Posttest $1>$ Pretest; Posttest $1=$ Posttest 2 \\
\hline & Phonol blending & 2,21 & 8.4 & $0.005^{*}$ & [Posttest $1>$ Pretest; Posttest $2>$ Pretest; Posttest $1=$ Posttest 2] \\
\hline CELF & Following Directions & 2,21 & 5.8 & $0.04^{\star}$ & Posttest 1 and Posttest $2>$ Pretest; Posttest $1=$ Posttest 2 \\
\hline BKB-SIN & & 2,18 & 4.9 & $0.03^{*}$ & Posttest $2>$ Pretest \\
\hline ANL & & 2,21 & 0.96 & 0.41 & No differences across three test sessions \\
\hline \multirow[t]{7}{*}{ LiSN-S } & SRT Conditions & & & & \\
\hline & Main effect: time & 2,42 & 2.1 & 0.017 & No differences across three test sessions \\
\hline & Main effect: condition & 1,42 & 81.7 & $0.0001^{*}$ & High-cue SRT better than low-cue SRT \\
\hline & $\begin{array}{l}\text { Interaction effect } \\
\text { Advantage Conditions }\end{array}$ & 1,42 & 1.1 & 0.37 & No interaction effect \\
\hline & Main effect: time & 1,63 & 1.3 & 0.31 & No differences across three test sessions \\
\hline & Main effect: condition & 2,63 & 36.6 & $0.0008^{*}$ & Total $>$ spatial $>$ talker condition \\
\hline & Interaction effect & 4,63 & 2.3 & 0.09 & No interaction effect \\
\hline \multirow[t]{3}{*}{ DWT } & Main effect: time & 2,42 & 20.5 & $0.001^{*}$ & Posttest 1 and Posttest $2>$ Pretest \\
\hline & Main effect: ear & 1,42 & 3.4 & 0.11 & Nondominant ear $<$ all other conditions \\
\hline & Interaction effect & 2,42 & 6.8 & $0.01^{*}$ & Dominant ear Pretest $<$ dominant ear Posttest 2 \\
\hline \multirow[t]{14}{*}{ RDDT } & One-digit Pairs & & & & \\
\hline & Main effect: time & 2,42 & 12.9 & $0.001^{*}$ & Posttest 1 and Posttest $2>$ Pretest \\
\hline & Main effect: ear & 1,42 & 5.9 & 0.051 & Nondominant ear Pretest $<$ all conditions \\
\hline & $\begin{array}{l}\text { Interaction effect } \\
\text { Two-digit Pairs }\end{array}$ & 2,42 & 5.2 & $0.02^{*}$ & Dominant ear Pretest $<$ dominant ear Posttest 2 \\
\hline & Main effect: time & 2,42 & 15.2 & $0.0005^{*}$ & Posttest 1 and Posttest $2>$ Pretest \\
\hline & Main effect: ear & 1,42 & 8.1 & $0.03^{*}$ & Dominant ear $>$ nondominant ear \\
\hline & Interaction effect & 2,42 & 11.3 & $0.002^{*}$ & Nondominant ear Pretest $<$ all other conditions \\
\hline & Three-Digit Pairs & & & & \\
\hline & Main effect: time & 2,42 & 13.8 & $0.0008^{*}$ & Posttest 1 and Posttest $2>$ Pretest \\
\hline & Main effect: ear & 1,42 & 9.8 & $0.02^{*}$ & Dominant ear $>$ nondominant ear \\
\hline & $\begin{array}{l}\text { Interaction effect } \\
\text { Advantage-All Pairs }\end{array}$ & 2,42 & 5.0 & $0.03^{*}$ & Nondominant ear Pretest $<$ all other conditions \\
\hline & Main effect: time & 2,63 & 17.2 & $0.0003^{*}$ & Posttest 1 and Posttest $2>$ Pretest \\
\hline & Main effect: pairs & 2,63 & 1.8 & 0.20 & \\
\hline & Interaction effect & 4,63 & 0.59 & 0.67 & \\
\hline
\end{tabular}

Notes: Data were analyzed with repeated measures ANOVA; post hoc comparisons were conducted with the Tukey-Kramer multiple comparisons test. $\mathrm{N}=7$. ANOVA = analysis of variance; Comp = comprehension; Mem = memory; Num = number; Phonol = phonological. *Statistically significant.

Pretest performance with normative data by age in the BKB-SIN test manual (2005), 11 of the 15 participants had speech-in-noise thresholds that were worse than most similarly aged neurotypical peers (i.e., $>1$ SD and worse thresholds than $68 \%$ of children his/her age), consistent with previous research (Alcántara et al, 2004; Schafer et al, 2013). After training, 6 of these 11 participants improved their thresholds to within one SD of the BKB-SIN normative data. Thus, despite the lack of a significant group finding on the BKB-SIN test, individual data suggest that the APT program improved performance for some individuals. In addition, when the RM technology was in use, speech recogni- tion in noise and the acceptance of background noise was significantly improved for all participants, suggesting that this type of technology is beneficial in noisy listening situations (Knecht et al, 2002; Cruckley et al, 2011).

\section{Study Limitations}

Limitations of this study relate to sample size, age range of the participants, heterogeneity of the ASD population, lack of a control group or repeated baseline measure, limited control over hours of RM technology use, poor response rate for the teacher questionnaires, 
and the inability to determine the relative contributions of the three interventions. Continued data collection from individuals diagnosed with ASD and age-matched neurotypical peers will address some of these limitations. However, it is important to note that in any sample of individuals with ASD, multiple factors will contribute to the variability in performance. These factors include age, coexisting disabilities, auditory attention, hours of RM technology use per day, and maturation of auditory skills (particularly for dichotic testing). Given the heterogeneity (i.e., spectrum of abilities) in the ASD population and the range of educational environments in which children with ASD are taught, most of these factors are difficult to control. In addition, it is challenging to recruit and retain participants and families who are willing and able to complete training studies that require a substantial time commitment (approximately 42 days).

\section{Clinical Implications}

Although it was important to test the APT program in a laboratory-based study, the time commitment that was required for the participants and families was a substantial barrier. However, the investigators believe that it is feasible to implement each of these interventions through clinical or school-based audiology services and through speech-language therapy. Clinical or educational audiologists can fit and monitor the RM technology, and audiologists or speechlanguage pathologists can administer the web-based CAPDOTS program. In the present study, it is evident that CAPDOTS improved binaural integration, and multiple studies, including the present, support the use of RM technology for improving classroom and self-perceived listening abilities (Schafer et al, 2013; 2016; Rance et al, 2014). Consistent use of the RM technology for a longer period of time (i.e., $>12$ weeks) may result in even greater benefits than those measured in the present study (Friederichs and Friederichs, 2005; Johnston et al, 2009; Hornickel et al, 2012; Smart et al, 2017). Implantation of the one-one-one auditory training in background noise with a speechlanguage pathologist or audiologist is also viable in a school- or therapy-based setting. Manuscript preparation is underway to provide more detailed information about implementing the one-on-one auditory training and expected training improvements over time in a group of individuals with ASD.

To summarize, this study provides evidence that the APT program consisting of computerized dichotic training, one-on-one therapist-directed auditory training, and the use of RM technology at home and in the classroom significantly enhanced auditory processing abilities and working memory in 15 children and young adults diagnosed with ASD.

Acknowledgments. CAPDOTS provided the auditory training program and Phonak loaned the participants the remote microphone technology used during the study.

\section{REFERENCES}

Alcántara JI, Weisblatt EJ, Moore BC, Bolton PF. (2004) Speechin-noise perception in high-functioning individuals with autism or Asperger's syndrome. J Child Psychol Psychiatry 45(6): $1107-1114$

American Psychiatric Association. (2013) Diagnostic and Statistical Manual of Mental Disorders. Washington, DC: American Psychiatric Association.

Anderson K, Smaldino J, Spangler C. (2011) Listening Inventory for Education-Revised (L.I.F.E.-R.). https://successforkidswithhearingloss. com/. Accessed January 1, 2015.

ANL. (2009) Acceptable noise level: ANL. Kelowna: Cosmos Distributing Co. Ltd.

Ashburner J, Rodger S, Ziviani J. (2008) Sensory processing and classroom emotional, behavioral, and educational outcomes in children with autism spectrum disorder. Am J Occup Ther 62: $564-573$

BKB-SIN. (2005) BKB-SIN: Bamford-Kowal-Bench Speech in Noise Test. Elk Grove Village, IL: Etymotic Research.

Cameron S, Dillon H. (2007) Listening in Spatialized Noise - Sentence Test (Version 2.400) [Computer Software]. Sydney, Australia: National Acoustic Laboratories.

CAPDOTS-Integrated. (2018) [Computer Software]. capdots.com.

Cruckley J, Scollie S, Parsa V. (2011) An exploration of non-quiet listening at school. J Educ Audiol 17:23-35.

Denman I, Banajee M, Hurley A. (2015) Dichotic listening training in children with autism spectrum disorder: a single subject design. Int $J$ Audiol 54(12):991-996.

Dichotics, Inc. (n.d.) Audia Dichotic (Version 1.4.4) [Computer Software]. dichoticsinc.com/\#software.

Dunn W. (2014) Sensory Profile 2 Manual. San Antonio, TX: Pearson.

Friederichs E, Friederichs P. (2005) Electrophysiologic and psychoacoustic findings following one-year application of a personal ear-level FM device in children with attention deficit and suspected central auditory processing disorder. J Educ Audiol 12:31-36.

Hammill DD, Pearson NA, Weiderholt JL. (2009) Comprehensive Test of Nonverbal Intelligence. 2nd ed. Austin, TX: PRO-ED.

Hayashi M, Takamura I, Kohara H, Yamazaki K. (1989) A neurolinguistic study of autistic children employing dichotic listening. Tokai J Exp Clin Med 14(4):339-345.

Hornickel J, Zeker SG, Bradlow AR, Kraus N. (2012) Assistive listening devices drive neuroplasticity in children with dyslexia. Proc Natl Acad Sci USA 109(41):16731-16736.

Hugdahl K, Westerhausen R, Alho K, Medvedev S, Laine M, Hämäläinen H. (2009) Attention and cognitive control: unfolding the dichotic listening story. Scand J Psychol 50(1):11-22. 
Johnston K, John A, Kreisman N, Hall J, Crandell C. (2009) Multiple benefits of personal FM system use by children with auditory processing disorder (APD). Int $J$ Audiol 48(6):371-383.

Kozou H, Azouz HG, Abdou RM, Shaltout A. (2018) Evaluation and remediation of central auditory processing disorders in children with autism spectrum disorders. Int $J$ Pediatr Otorhinolaryngol 104:36-42.

Knecht H, Nelson P, Whitelaw G, Feth L. (2002) Background noise levels and reverberation times in unoccupied classrooms: predictions and measurements. Am J Audiol 11(2):65-71.

Loo JH, Rosen S, Bamiou DE. (2016) Auditory training effects on the listening skills of children with auditory processing disorder. Ear Hear 37(1):38-47.

Macizo P, Soriano MF, Paredes N. (2016) Phonological and visuospatial working memory in autism spectrum disorders. J Autism Dev Disord 46(9):2956-2967.

Martin NA, Brownell R. (2005) Test of Auditory Processing Skills. 3rd ed. Novato, CA: Academy Therapy Publications.

Moncreiff D. (2015) Age- and gender-specific normative information from children assessed with a dichotic words test. J Am Acad Audiol 26:632-644.

Moncreiff DW, Wilson RH. (2009) Recognition of randomly presented one-, two-, and three-pair dichotic digits by children and young adults. J Am Acad Audiol 20:58-70.

Moncrieff D, Keith W, Abramson M, Swann A. (2017) Evidence of binaural integration benefits following ARIA training for children and adolescents diagnosed with amblyaudia. Int J Audiol 56(8):580-588.

Rance G, Chisari D, Saunders K, Rault JL. (2017) Reducing listening-related stress in school-aged children with autism spectrum disorder. J Autism Dev Disord 47(7):2010-2022.

Rance G, Saunders K, Carew P, Johansson M, Tan J. (2014) The use of listening devices to ameliorate auditory deficit in children with autism. J Pediatr 164(2):352-357.

Schafer EC, Bryant D, Sanders K, Baldus N, Algier K, Lewis A, Traber J, Layden P, Amin A. (2014a) Fitting and verification of frequency modulation systems on children with normal hearing. $J$ Am Acad Audiol 25(6):529-540.

Schafer EC, Mathews L, Mehta S, Hill M, Munoz A, Bishop R, Moloney M. (2013) Personal FM systems for children with autism spectrum disorders (ASD) and/or attention-deficit hyperactivity disorder (ADHD): an initial investigation. J Commun Disord 46(1):30-52.
Schafer EC, Traber J, Layden P, Amin A, Sanders K, Bryant D, Baldus N. (2014b) Use of wireless technology for children with auditory processing disorders, attention-deficit hyperactivity disorder, and language disorders. Sem Hear 35(3):193205 .

Schafer EC, Wright S, Anderson C, Jones J, Pitts K, Bryant D, Watson M, Box J, Neve M, Mathews L, Reed MP. (2016) Assistive technology evaluations: remote-microphone technology for children with autism spectrum disorder. J Commun Disord 64:1-17.

Scollie S, Seewald R, Cornelisse L, Moodie S, Bagatto M, Laurnagaray D, Beaulac S, Pumford J. (2005) The desired sensation level multistage input/output algorithm. Trends Amplif 9(4): 159-197.

Smart JL, Purdy SC, Kelly AS. (2017) Impact of personal frequency modulation systems on behavioral and cortical auditory evoked potential measures of auditory processing and classroom listening in school-aged children with auditory processing disorder. J Am Acad Audiol 29(7):568-586.

Smoski WJ, Brunt MA, Tannahill JC. (1998) Children's Auditory Performance Scale. Tampa, FL: Educational Audiology Association.

Tomchek SD, Dunn W. (2007) Sensory processing in children with and without autism: a comparative study using the short sensory profile. Am J Occup Ther 61(2):190-200.

Vogan V, Francis K, Morgan B, Smith ML, Taylor M. (2018) Load matters: neural correlates of verbal working memory in children with autism spectrum disorder. J Neurodev Disord 10:19.

Wang Y, Zhang YB, Liu LL, Cui JF, Wang J, Shum DH, van Amelsvoort T, Chan RC. (2017) A meta-analysis of working memory impairments in autism spectrum disorders. Neuropsychol Rev 27(1):46-61.

Weckstein SM, Weckstein EJ, Parker CD, Westerman MW. (2017) A retrospective chart analysis with follow-up of Cogmed Working Memory Training in children and adolescents with autism spectrum disorder. Med Sci Monit Basic Res 16(23): $336-343$.

Weihing J, Musiek F. (2014) Dichotic interaural intensity difference (DIID) training. In: Chermak G, Musiek FE, eds. Handbook of Central Auditory Processing Disorders. 2nd ed. San Diego, CA: Plural Publishing, 225-242.

Wiig EH, Semel E, Secord WA. (2013) Clinical Evaluation of Language Fundamentals. 5th ed. Bloomington, IN: NCS Pearson. 